\title{
Stigma and discrimination among health care providers towards people living with HIV/AIDS (PLWHA)
}

\author{
Mohamed Osman Elamin ${ }^{1}$, Yahia Raja'a ${ }^{2}$, Hamed Ademola Adetunji ${ }^{3}$, Sufian Khalid ${ }^{4}$, Remah Siddiq \\ ${ }^{1,2,3}$ Faculty of Public Health \& Health Informatics, Umm Al Qura University, KSA \\ ${ }^{4,5}$ Faculty of Medicine, Nile Valley University, Sudan
}

\section{Article Info \\ Article history: \\ Received Dec 10, 2018 \\ Revised Jan 11, 2019 \\ Accepted Feb 19, 2019}

\section{Keywords:}

Discrimination

Healthcare provider

PLWHA

River Nile

Stigma,

\begin{abstract}
Stigma and discrimination among Medical Care Providers (MCPs) towards HIV patients is a common observed problem that can compromise effectiveness of prevention and treatment efforts by discouraging individuals from being tested or seeking information on how to protect themselves and others. This research aimed to determine the existence of stigma and discrimination among health care providers towards people living with HIV and AIDS (PLWHA) in River Nile state. A descriptive Cross sectional hospital based study conducted in Atbara, Edamer and Berber hospitals. Questionnaire containing six parts covering the personal data, knowledge about HIV, attitude, availability of PPDs and discriminatory practices of MCPs was used. The data was analyzed using the SPSS. Three hundred and nighty participated consisting of 136 doctors, 219 nurses, and 35 midwives. Out of these, $68.2 \%$ of participants had overall satisfactory knowledge, $30 \%$ had good knowledge, while only $1.8 \%$ had poor knowledge. Majority $(74.4 \%)$ stated that MCPs were discriminatory in their practices towards HIV patients. There was a correlation between common discriminatory practices and total attitude, and availability of PPDs $(\mathrm{p}<0.05)$. No correlation between the common discriminatory practices and total knowledge scores. Discriminatory practices do exist among MCPs towards PLWHA in River Nile state.
\end{abstract}

Copyright $\odot 2019$ Institute of Advanced Engineering and Science. All rights reserved.

\section{Corresponding Author:}

Hamed Ademola Adetunji,

Department of Epidemiology, Faculty of Public Health \& Health Informatics, Umm Al Qura University, Makkah Al Mukarramah, KSA.

Email: hamed.tunji@gmail.com / haadetunji@uqu.edu.sa.1

\section{INTRODUCTION}

The (HIV/AIDS) epidemic has been accompanied by stigma and discrimination since its inception [1] and their associated realities have compounded the effects of the epidemic over the past 25 years [2]. Increasingly, HIV/AIDS-related stigma and discrimination are acknowledged as one of the greatest challenges to slowing the spread of the disease [3-4]. The ramifications of AIDS-related stigma and discrimination are numerous. Perceived and enacted stigma can place a huge psychological burden on an infected individual and thereby contribute to a decline in health status [5-6] Stigmatizing attitudes and discriminatory practices of family members and health providers prevent those infected from receiving adequate treatment, care, and support [7]. Stigma has often been associated with disfiguring or incurable diseases, in particular, diseases that society perceives to be caused by the violation of social norms, including those that sanction sexual behavior. HIV/AIDS is a good example of this type of disease [8-9]. The health care setting is a particularly conspicuous context for HIV/AIDS-related stigma and discrimination [10]. In this context people living with HIV or AIDS (PLWHA) often discover their status, and it is where people living with HIV have the potential to gather information about how to care for them and prevent transmission to others, as well as get treatment and care. Because of stigma, there have been various reports of HIV 
positive people receiving inferior care or being denied care altogether [11-12]. Various studies have demonstrated that AIDS-related stigma is a common phenomenon worldwide that occurs in a variety of contexts, including the family, community, workplace, and health care settings [13-14]. Actions that express stigma are often referred to as "discrimination" or "behavior in which a distinction is made against people that results in the person being treated unfairly or unjustly on the basis of them belonging, or being perceived to belong to a particular group" [14-15]. Fear of stigma and discrimination keeps people from learning their HIV status, and if positive, from disclosing their status to others and accessing health services. Since the number of people living with human immunodeficiency virus (HIV)/acquired immunodeficiency syndrome (AIDS) (PLWHA) is increasing all over the world, medical care providers are positioned to respond with needed services and care [14]. However, accessing health care can be a challenge for people who are HIV positive because health sector has been identified as one of the areas in which stigma and discrimination occur toward people living with HIV/AIDS worldwide [16].

Stigma and discrimination against PLWHA in health facilities compromise the effectiveness of prevention and treatment efforts by discouraging individuals from being tested or seeking information on how to protect themselves and others and affecting access to and utilization of health care service [17-19]. Stigma and discrimination have many negative consequences in the life quality of PLWHA and reduce the quality of treatment and health care they received [20]. In Sudan, WHO suggest growing and hidden epidemic and for every known case, 15 cases lie undetected. WHO considered discrimination against PLWHA in health facilities as a major factor responsible for increasing risk behavior and underreporting of cases in Sudan [21-22]. Due to the importance of this issue and as the result of Sudanese government's commitment to HIV/AIDS and STD Prevention and Care, legislation agents discrimination toward PLWHA (including health field) was released in 2009 [23-24]. On the other hand MCPs in the case of dealing with HIV patients put themselves at high risk of through lack of protective devices, or not adhering to known safety measures or other unforeseen circumstances and their perception of exposure to risk can influence the management of patients and diseases [25]. So the interests and well-being of MCPs are very important for establishing an environment free of stigma and discrimination in health field [26-28].

Since the level discriminatory practices, knowledge, attitude, perceived risk of MCPs toward HIV patients in River Nile state is unknown and there are no studies to the best of our knowledge that has addressed this issue, it is believed that this study will be unique in providing information that could be used for providing better health care to PLWHA especially in this area and similar settings where information about the welfare of the PLWHA is not readily available. This study therefore aim to explore and evaluate the KAP of medical care providers toward people living with HIV in public hospitals in River Nile state, Sudan in order to quantify the existence of stigma and discrimination against PLWHA. The existence of negative attitudes (stigma) toward PLWHAs among medical care providers will be quantified; availability of personal protective devices during medical practices will be assessed and the existence of discriminatory practices against PLWHAs will also be quantified. Finally, the relationships between provider knowledge, attitudes, availability of personal protective devices with common discriminatory practices toward PLWHAs will be assessed.

\section{RESEARCH METHOD}

The study is a descriptive Cross sectional study conducted between January, and March 2017 in River Nile State/north of Sudan in three major hospitals (Atbara, Edamer, and Berber). All medical care providers (doctors, nurses and midwifes) who were working in the Emergency, obstetrics, surgery, medicine, pediatrics, ophthalmology and ENT departments at the time of hospital visiting days. Three hundred and ninety medical care workers participated in the study. Questionnaire was developed form literature and measurements in the questionnaire based on previously accepted questions [29-32]. Before administrating the questionnaire it was translated to Arabic language and randomly distributed for pretesting to 20 medical care providers working in different departments (Emergency, Surgery, Obstetrics, Internal medicine and Pediatric) and finally modified according to notes of participants in the pretest questionnaire. The questionnaire consisted information on personal characteristics such as age, sex, occupation, qualification, hospital, department; knowledge about HIV/AIDS; attitude toward PLWHA; availability of personal protective devices; and discriminatory practices.

Knowledge of HIV/AIDS was assessed by using 12 multiple choice questions with 24 items. There were 3-5 choices in each question except questions of mode of transmission and prevention which had 10-11 choices with multiple correct answers. Participants earned one point for each correct answer. So the total knowledge scores were the total number of points earned out of 24 points. Provider's attitude toward HIV/AIDS patients was assessed by using a 27 -statement of attitude and beliefs scale. Participants were asked to rate the degree to which they agree with each statement on a five point Likert 
scale ( $1=$ strongly disagree, $2=$ disagree, $3=$ not sure, $4=$ agree and $5=$ strongly agree). Total attitude scores equaled the sum of the scores on all 27 statements with a maximum of 135 points. The availability of personal protective devices during work (gloves, masks, aprons and goggles) was assessed by using 4 statements. Participants were asked to rate how often personal protective devices are available. Answer of each statement was scored by using five-point scale (1=never, 2=rarely, 3=sometimes, $4=$ frequently, 5=always). Total availably of PPDs scores equaled the sum of the scores on the four statements with a maximum of 20 points. The Common discriminatory practice was assessed by using nine statements which used to assess the occurrence of discrimination among medical care providers. Providers were asked to rate how often (never, rarely, sometimes, frequently, always) they thought providers behaved in such way when providing medical care to patient with HIV. Answer of each statement was scored by using five-point scale ( $1=$ never, $2=$ rarely, $3=$ sometimes, $4=$ frequently, $5=$ always). The total discriminatory practices scores equaled the sum of the scores on the 9 statements with maximum of 45 points.

The data were analyzed with SPSS software (v. 15.0). Descriptive analyses described the sample of providers in terms of personal characteristics such as age, sex, occupation, qualification, hospital, department, experience in providing care to PLWHA and receiving training on HIV. One-way-ANOVA test and independent T-test were used for testing difference in means and association between knowledge, attitude and discriminatory practices with personal characteristic of participants. Correlation was used to assess the relationship between discriminatory practices and knowledge, attitude. For all analysis $\mathrm{p}$ value of less than 0.05 were considered statistically significant. Ethical clearance certificate from Research and Ethics Committee in faculty of medicine and ministry of health in River Nile State was obtained. Participants were asked to read the consent form and sign on it if they accepted to participate in the study or not

\section{RESULTS AND DISCUSSION}

\subsection{Results}

Socio-demographic characteristics of the healthcare providers who participated in this study are presented in Table 1 According to Table 1, female participants in the study were in the majority (70\%) while the rest $(30 \%)$ were males. Majority was in the age group 20-30 years (47.2\%); followed by 31-40 years $(39.2 \%)$, while the least $(3.8 \%)$ were 51-60 years. Majority $(59.7 \%)$ had bachelor degrees, followed by diploma after secondary school $(17.4 \%)$ with the least of them $(9.7 \%)$ having diploma after primary school (9.7\%). Professions include nurses (59.7\%), doctors (34.9\%) and midwives $9 \%$. Years of working experience were below 5 years (47.4\%), 6-10 years $(26.2 \%)$, and 11-20 years and above 30 years. Departments of the participants are also display in Table 1 showing $18.7 \%$ of participants were working in the obstetric department, $16.4 \%$ in surgery, $23.1 \%$ working in internal medicine, $15.6 \%$ in pediatrics and $24.6 \%$ working in emergency department .1\% were working in the ENT department and $0.5 \%$ in ophthalmology department. Participants' results on whether they had training on HIV shows that majority of the medical care providers $(82.8 \%)$ did not receive training in HIV, while just $17.2 \%$ of participants stated that they received training. On whether the participants involved in direct care of HIV patients, majority (76.9\%) reported to have provided care to HIV positive patients, while nearly a third (23.1\%) didn't. Results are presented in Table 2 show that participant had weak knowledge on exposure prevention. For example $18.7 \%$ got correct knowledge whether instrument used on HIV positive patients can be sterilized and used again, 9.2\% answered correctly that equipment used for PLWHA don't need to disinfected separately or more rigorously while only $21.5 \%$ had correct answers on not recapping needles when used.

HIV-Related Knowledge of Healthcare Providers, River Nile State, Sudan is shown in Table 2 otherwise wrong beliefs about HIV Transmission and Prevention Strategies are shown in Table 3. Table 3 informs that participants in this study held a range of wrong beliefs that include kissing (56.2\%) and blood donation (48.2\%) can transmit HIV. Also (59.7\%) believed HIV patients should have separate equipment. The participants overall knowledge of HIV was satisfactory (68.2\%) good (30\%), and poor $(1.8 \%)$ represented by of participants.

Table 4 presents comparison of mean knowledge score of participants by socio-demographic characteristics. The $\mathrm{p}$ value is significant in the gender, age, hospital, occupation and qualifications. There was no association between the working department and overall knowledge. Level of attitude was categorized into 3 groups around 327 of participants (83.8\%) had positive attitude (>60\% scores), 57 (14.6\%) had unclear attitude $(>40 \%$ and $\leq 60 \%$ scores) while only $6(1.5 \%)$ had negative attitude ( $\leq 40 \%$ scores). Meanwhile attitude of participants according to the level of blame of HIV patients is presented in Table 5.

Table 6 presents comparison of mean attitude mean score of participants by socio-demographic characteristics. The p-value is significant in the gender, age, occupation, qualifications, hospital, training, and knowledge. There was no association between the working department and attitude of the participants. 
Table 1. Socio-demographic characteristics of healthcare providers, River Nile State, Sudan

\begin{tabular}{|c|c|c|}
\hline Variable & Number & Percent \\
\hline \multicolumn{3}{|l|}{ Gender } \\
\hline Male & 117 & 30.0 \\
\hline \multicolumn{3}{|l|}{ Age in years } \\
\hline 20-30 year & 180 & 46.2 \\
\hline $31-40$ year & 155 & 39.2 \\
\hline $41-50$ year & 40 & 10.3 \\
\hline 51-60 year & 15 & 3.8 \\
\hline Female & 273 & 70.0 \\
\hline \multicolumn{3}{|l|}{ Working years } \\
\hline $0-5$ years & 185 & 47.4 \\
\hline $6-10$ years & 102 & 26.2 \\
\hline $11-20$ year & 87 & 22.3 \\
\hline 21-30 year & 9 & 2.3 \\
\hline$>30$ year & 7 & 1.8 \\
\hline \multicolumn{3}{|l|}{ Qualification } \\
\hline Bachelor & 233 & 59.7 \\
\hline diploma after secondary school & 68 & 17.4 \\
\hline diploma after primary school & 38 & 9.7 \\
\hline secondary school & 51 & 13.1 \\
\hline \multicolumn{3}{|l|}{ Profession } \\
\hline doctor & 136 & 34.9 \\
\hline nurse & 219 & 56.2 \\
\hline midwife & 35 & 9.0 \\
\hline \multicolumn{3}{|l|}{ Providing care for HIV patient } \\
\hline Yes & 300 & 76.9 \\
\hline No & 90 & 23.1 \\
\hline \multicolumn{3}{|l|}{ Training } \\
\hline Yes & 67 & 17.2 \\
\hline No & 323 & 82.8 \\
\hline \multicolumn{3}{|l|}{ Department } \\
\hline emergency department & 96 & 24.6 \\
\hline internal medicine & 90 & 23.1 \\
\hline Paediatrics & 61 & 15.6 \\
\hline Surgery & 64 & 16.4 \\
\hline obstetric department & 73 & 18.7 \\
\hline ENT & 4 & 1.0 \\
\hline Ophthalmology & 2 & 0.5 \\
\hline
\end{tabular}

Table 2. HIV-related knowledge of healthcare providers, River Nile State, Sudan

\begin{tabular}{lcc}
\hline \multicolumn{1}{c}{ Item } & Correct responses \\
& $\mathrm{N}$ & $(\%)$ \\
\hline HIV transmission knowledge & 363 & 93.1 \\
Blood and semen are the most body fluids that transmit HIV & \\
HIV can be transmitted by: (multiple correct answers) & 318 & 81.5 \\
Tattooing & 385 & 98.7 \\
Sexual intercourse(vaginal sex) & 274 & 70.3 \\
Homosexual (anal sex) & 336 & 86.2 \\
Accidental needle stick & 222 & 56.9 \\
Exposure to blood when taking care of patients & 343 \\
From mother to child (vertical transmission) & 357 & 87.9 \\
Receiving blood (blood transfusion) & 91.5 \\
Exposure prevention knowledge & 73 \\
Instrument used on HIV positive patients can be sterilized and used again & 18.7 \\
Equipment used for PLWHA don't need to disinfected separately or more rigorously & 36 \\
In what ways can HIV be prevented? (multiple correct answers) & 9.2 \\
Use of gloves during invasive procedure & 355 \\
Use of condom with sex & 353 \\
Properly sterilizing instrument and equipment & 379 \\
Not recapping needles & 84 \\
Use of gloves when handling patient specimens & 91.0 \\
Use of eye protection (goggles) when delivering babies & 349 \\
Abstinence & 74 \\
Risk association & 367 \\
Highest risk for contracting HIV at work is accidental needle prick & 87.2 \\
Older men are at a lower risk for HIV infection than general public & 89.5 \\
\hline
\end{tabular}


Table 3. Wrong beliefs about HIV transmission and prevention strategies

\begin{tabular}{ccc}
\hline Wrong beliefs & Number & Percent \\
Mode of transmission & & \\
\hline Blood donation & 188 & 48.2 \\
Mosquito biting & 22 & 5.6 \\
Greeting someone with a kiss on the cheek & 219 & 56.2 \\
Sharing cups and teaspoons & 57 & 14.6 \\
$\quad$ Prevention strategies & 27 & 6.9 \\
Not providing care to PLWHA & 306 & 78.5 \\
Use of gloves when taking care of patients suspected to be HIV & 233 & 59.7 \\
Use of separated equipment for PLWHA & & \\
\hline
\end{tabular}

Table 4. Comparison of mean composite knowledge scores

\begin{tabular}{|c|c|c|c|c|}
\hline Providers characteristics & $\mathrm{N}$ & Mean scores $\%$ & Std. Deviation & $\mathrm{P}$ value \\
\hline \multicolumn{5}{|l|}{ Sex } \\
\hline Male & 117 & 70.6222 & 8.54803 & \multirow{2}{*}{0.000} \\
\hline Female & 273 & 65.2689 & 9.82488 & \\
\hline \multicolumn{5}{|l|}{ Age } \\
\hline 20-30 year & 180 & 69.9361 & 10.31655 & \multirow{3}{*}{0.000} \\
\hline $31-40$ year & 155 & 61.6955 & 6.88224 & \\
\hline 41-50 year & 40 & 71.6850 & 9.11686 & \\
\hline $51-60$ year & 15 & 70.8333 & 5.89427 & \\
\hline \multicolumn{5}{|l|}{ Hospital } \\
\hline Atbara hospital & 236 & 66.4229 & 9.72647 & \multirow{3}{*}{0.000} \\
\hline Edamer hospital & 106 & 67.8943 & 10.09356 & \\
\hline Berber hospital & 48 & 66.8458 & 9.21493 & \\
\hline \multicolumn{5}{|l|}{ Department } \\
\hline emergency department & 96 & 63.3812 & 8.14396 & \multirow{7}{*}{0.130} \\
\hline internal medicine & 90 & 67.9178 & 10.11954 & \\
\hline Paediatrics & 61 & 69.9492 & 8.96753 & \\
\hline Surgery & 64 & 71.5578 & 10.36009 & \\
\hline obstetric department & 73 & 62.8986 & 8.57361 & \\
\hline ENT & 4 & 75.0000 & 3.42929 & \\
\hline Ophthalmology & 2 & 72.9000 & 2.96985 & \\
\hline \multicolumn{5}{|l|}{ Occupation } \\
\hline Doctor & 136 & 69.8250 & 11.45290 & \multirow{3}{*}{0.000} \\
\hline Nurse & 219 & 66.1046 & 8.46700 & \\
\hline Midwife & 35 & 60.2314 & 5.09964 & \\
\hline \multicolumn{5}{|l|}{ Qualifications } \\
\hline Bachelor & 233 & 69.6571 & 9.98299 & \multirow{5}{*}{0.000} \\
\hline diploma after secondary school & 68 & 62.4485 & 9.05805 & \\
\hline diploma after primary school & 38 & 63.8316 & 9.33708 & \\
\hline secondary school & 51 & 62.3333 & 3.72825 & \\
\hline Total & 390 & & & \\
\hline
\end{tabular}

Figure 1 presents the HIV related knowledge of healthcare providers by HIV Topics. Good knowledge was more dominant in the topic of mode of transmission (83.2\%), knowledge on prevention strategies, virology and presenting symptoms are about equal with 59.9\%, $59.8 \%$ and 58.7\% respectively.

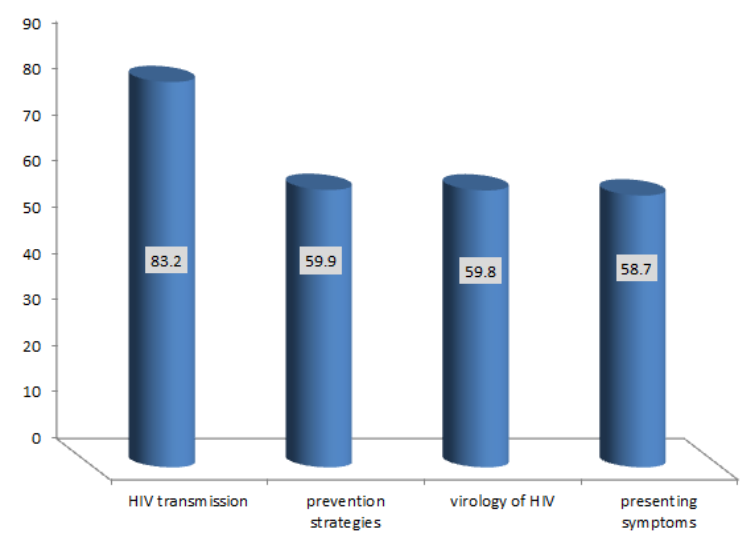

Figure 1. Knowledge by HIV topics 
Table 5. Level of blame among participants toward PLWHA

\begin{tabular}{ccc}
\hline Level of blame & Number & Percent \\
\hline High & 225 & 57.7 \\
Unclear & 136 & 34.9 \\
Low & 29 & 7.4 \\
\hline
\end{tabular}

Table 6. Attitude mean score by personal characteristic

\begin{tabular}{|c|c|c|c|c|}
\hline Provider characteristics & $\mathrm{N}$ & Mean & STD. & $\mathrm{P}$ value \\
\hline \multicolumn{5}{|l|}{ Sex } \\
\hline Male & 117 & 70.0060 & 6.76367 & \multirow{3}{*}{0.000} \\
\hline Female & 273 & 67.8264 & 9.63093 & \\
\hline \multicolumn{4}{|l|}{ Age } & \\
\hline $20-30$ & 180 & 70.7739 & 7.87231 & \multirow{4}{*}{0.000} \\
\hline $31-40$ & 155 & 65.6639 & 6.10294 & \\
\hline $41-50$ & 40 & 69.5650 & 17.34467 & \\
\hline $51-60$ & 15 & 67.1667 & 2.85349 & \\
\hline \multicolumn{5}{|l|}{ Occupation } \\
\hline Doctor & 136 & 70.9544 & 7.36643 & \multirow{3}{*}{0.000} \\
\hline Nurse & 219 & 68.7991 & 7.09245 & \\
\hline Midwife & 35 & 56.8714 & 14.41183 & \\
\hline \multicolumn{5}{|l|}{ Qualifications } \\
\hline Bachelor & 233 & 70.8867 & 7.44163 & \multirow{5}{*}{0.000} \\
\hline diploma after secondary school & 68 & 62.8603 & 12.62142 & \\
\hline diploma after primary school & 38 & 70.2132 & 4.10340 & \\
\hline secondary school & 51 & 63.6882 & 6.32303 & \\
\hline \multicolumn{4}{|l|}{ Hospital } & \\
\hline Atbara hospital & 236 & 68.3733 & 8.57344 & \multirow{3}{*}{0.446} \\
\hline Edamer hospital & 106 & 68.0632 & 8.92937 & \\
\hline Berber hospital & 48 & 69.9271 & 10.47594 & \\
\hline \multicolumn{5}{|l|}{ Department } \\
\hline emergency department & 96 & 67.7292 & 6.93854 & \multirow{7}{*}{0.777} \\
\hline internal medicine & 90 & 68.3011 & 6.39003 & \\
\hline Paediatrics & 61 & 69.3852 & 7.07771 & \\
\hline Surgery & 64 & 73.2375 & 7.53311 & \\
\hline obstetric department & 73 & 64.7890 & 13.65513 & \\
\hline ENT & 4 & 66.8750 & 4.53606 & \\
\hline Ophthalmology & 2 & 70.7000 & 8.90955 & \\
\hline \multicolumn{5}{|l|}{ Training on HIV } \\
\hline Yes & 67 & 63.8403 & 5.51730 & \multirow{2}{*}{0.000} \\
\hline No & 323 & 69.4427 & 9.18653 & \\
\hline \multicolumn{5}{|l|}{ Knowledge } \\
\hline Good knowledge & 117 & 73.2325 & 6.46007 & \multirow{4}{*}{0.000} \\
\hline Satisfactory knowledge & 266 & 66.4571 & 9.12823 & \\
\hline Poor knowledge & 7 & 65.9286 & 6.14375 & \\
\hline Perceived risk & & & & \\
\hline High perceived risk & 115 & 73.2496 & 6.47804 & \multirow{3}{*}{0.000} \\
\hline Unclear perceive risk & 268 & 66.4340 & 9.11729 & \\
\hline Low perceived risk & 7 & 68.4714 & 5.89738 & \\
\hline
\end{tabular}

About 290 of participants $(74.4 \%)$ assigned that there is discriminatory practices among medical care providers towards people living with HIV and AIDS while only 100 of participants assigned there is no discriminatory practice. The discriminatory practices were in the form of passive denial of services where Providers delay treatment or provide slower service for HIV positive patients $(79.5 \%)$ or postpone treatment /surgery for HIV patients as long as possible (86.7\%). Others include substandard treatment such as Providers administer medication but don't touch or physically examine patients with HIV/AIDS (73.1\%), providers try to cleverly deny admission of HIV positive patients but admission is not denied outright $(75.1 \%)$ or selective use of universal precautions in which providers use protective while dealing with HIV/AIDS patients like wearing gloves, gowns, or mask to do noninvasive physical exams on non-bleeding HIV positive patients even if patients does not have open sores $(89.9 \%)$ or use double gloves when preparing the body of a deceased HIV patient $(89.2 \%)$. On confidentiality of patients, providers do not maintain the confidentiality of HIV positive patients $(88.4 \%)$. There were correlation between common discriminatory practices and total attitude, and total availability of PPDs. However, there was no correlation between the common discriminatory practices and total knowledge score. 


\subsection{Discussion}

To best of our knowledge this is the first study about stigma and discrimination among health care providers towards people living with HIV and AIDS conducted in River Nile State. This study assessed the discriminatory practices, knowledge, availability of protective personal devices and attitudes among all medical care providers that have direct contact of HIV patient (doctors, nurses and midwives). The attitude part covered the level of blame, level of fear from being infected from HIV patient, level of desiring isolation of HIV patient, level of MCPs sympathy towards PLWHA.

The study revealed that majority of the medical care providers $(82.8 \%)$ did not receive training in HIV. This may lead to increase in stigma among MCPs towards the HIV patients. Providers who received training on HIV or involved in direct patient care had significantly higher knowledge scores than those who didn't and this is a similar result to the study conducted in Tanzania [22]. In this study the majority (74.4\%) admitted that there were discriminatory practices among MCPs towards HIV patients. The discriminatory practices were in the forms of Passive denial of services as $79.5 \%$ stated that providers delay treatment or provide slower service for HIV positive patients, $86.7 \%$ stated that providers postpone treatment/surgery for HIV patients as long as possible. Discriminatory practices occurred in the form of substandard treatments like administering medication but don't touch or physically examine patients with HIV/AIDS (73.1\%), trying to cleverly deny admission of HIV positive patients (75.1\%), using double gloves when preparing the body of a dead HIV patient $(89.2 \%)$, not maintaining the confidentiality of HIV positive patients $(82 \%)$. These are consistent with many studies conducted elsewhere such that of Sudan [33], Tanzania [34], Nigeria [35] and Rwanda [36]. The study in Sudan showed some discriminatory practices against PLWHA where $27.1 \%$ of respondents observed health workers avoiding HIV patients, 18.8 - 30.4\% observed less care provided to HIV positive patients, $44.9 \%$ observed health workers gossiping about the HIV status of patients, $72.5 \%$ reported seeing equipment being sterilized with extra caution from HIV positive patients and $87.4 \%$ of HCP wear gloves to carry out simple examination procedures on PLWHA [33]. As for Tanzania, the study showed that $47 \%$ of providers said that at least one discriminatory behavior occurred among their peers [34]. The Nigeria study showed discriminatory practices where $9 \%$ of health care professionals had refused care for HIV /AIDS patients and 9\% had refused admission to hospitals. Most of HCP (66\%) observed others refusing to care and $43 \%$ refusing admission. Four factors that may contribute to this behavior according to the study include lack of correct information about HIV/AIDS and prevention of infection, lack of protective materials needed for the practice of universal precautions, lack of materials needed to care for and treat patients with HIV/AIDS and prevailing attitudes about PLWHA [35]. In case of Rwanda, the study revealed that $89.1 \%$ of participants were aware of common practices that occurred by healthcare providers who discriminate against HIV patients. The study showed strong associations between provider attitudes and fears and their awareness of discriminatory practices that occur in facilities [36].

The overall knowledge of HIV was satisfactory (68.2\%) of participants, this results is similar to the study conducted in Yemen by Raja'a and colleagues among 211 health care givers in the child development project that showed half of the subjects (50\%) had satisfactory knowledge about HIV/AIDS [26] which differs from a Tanzania, study done among 204 HCPs that showed fair level of knowledge where $37 \%$ and $26 \%$ had satisfactory and good knowledge respectively.

Although majority $83.8 \%$ of MCPs had positive attitude, $14.6 \%$ had unclear attitude, and $1.5 \%$ had negative attitude towards HIV patients. The level of blame was high among MCPs and represented by $57.7 \%$. Other studies recorded negative attitudes towards PLWHA by healthcare staff looking after them. For example, in Sudan [33], in Yemen [37], in Saudi Arabia [38], in Kuwait [39], in Egypt [40] in Iran [41] and in India [42] that revealed negative attitude among $78 \%$ of $266 \mathrm{HCWs}$ who believed that HIV patients should be isolated from other patients and $77.9 \%$ felt worried about caring of PLWHA.

\section{CONCLUSION}

Medical care providers have overall satisfactory knowledge about HIV with some amount of poor knowledge related to presenting symptoms, virology, and prevention strategies. The higher knowledge was attained by doctors, while the lower knowledge was attained by midwifes and nurses. Medical care providers have overall positive attitude toward PLWHA with some amount of unclear attitude and very much lower amount of negative attitude. There was association between knowledge, perceived risk and attitude. The poor knowledge and higher perceived risk were the lower positive attitude. Discriminatory practice among all medical care providers was common, and the worst practices were among MCPs who work in obstetric department. Further qualitative study is required to determine the causes of discriminatory practice among medical care providers toward PLWHA. Information about HIV/AIDS in the curriculum of the health education institutes should be integrated and strengthened. Some emphasis on converting unclear attitude to positive attitude should be put in the mass media.

Int. J. Public Health Sci. Vol. 8, No. 1, March 2019: 36 - 44 


\section{REFERENCES}

[1] Herek G, and Glunt EK. An epidemic of stigma: public reaction to AIDS. American Psychology and Medicine. 1988:39(9):1259-366.

[2] UNAIDS. Reducing HIV Stigma and Discrimination: A critical part of national AIDS programmes. Geneva: Joint United Nations Programme on HIV/AIDS, 2007.

[3] Rao Gupta G. International Perspectives on Stigma. Presented at Health, Law, and Human Rights: Exploring the Connection, American Society of Law and Temple Philadelphia, PA,: University Beasly School of Law; September 30, 2001.

[4] Nyblade L. Addressing HIV-related stigma and resulting discrimination in Africa: A three-country study in Ethiopia, Tanzania, and Zambia. Information Bulletin, International Center for Research on Women, March 2002.

[5] UNAIDS. Report on the Global HIV/AIDS Epidemic. Geneva: UNAIDS, 2002.

[6] Mark L. Hatzenbuehler, Jo C. Phelan, Bruce G. Link, "Stigma as a Fundamental Cause of Population Health Inequalities", American Journal of Public Health 103, no. 5 (May 1, 2013): pp. 813-821. DOI: 10.2105/AJPH.2012.301069.

[7] Brown L, Macintyre K, and Trujillo L. Interventions to reduce HIV/AIDS stigma: What have we learned? AIDS Education and Prevention, 2003:15(1):49-69.

[8] Crandall C., Moriarty D. Physical illness, stigma and social rejection. British Journal of Psychology. 1995;34(1):67-83.

[9] Ogden J. \& Nyblade L. Common at its core: HIV-related stigma across continents. Washington, DC: International Centre for Research on Women 2005.

[10] Hargreaves, J.R. Krishnaratne, S. Mathema, H. Lilleston, P.S. Sievwright, K. Mandla, N. Mainga, T. Vermaak, R. Piwowar-Manning, E. Schaap, B. Donnell, D. Ayles, H. Hayes, R.J. Hoddinott, G; Bond V; and Stangl, A. Individual and community-level risk factors for HIV stigma in 21 Zambian and South African communities, AIDS, 32, 6, (783), (2018).

[11] National AIDS Control Organisation (NACO). Facts and figures. Internet communication,4,11,2011, att/ wwwnacoonlineorg.NACO: India.

[12] Reidpath D, Chan K. HIV discrimination: integrating the results from a six-country situational analysis in the Asia Pacific. AIDS Care Suppl 2. 2005:195-204.

[13] Horizons Program, International HIV/AIDS Alliance, and Tata Institute of Social Sciences. The involvement of people living with HIV/AIDS in the delivery of community-based prevention, care and support services in Maharashtra, India. A diagnostic study. Brighton, U.K: Population Council., 2003.

[14] Alkenbrack S, Chettra T, Forsythe S. The social and economic impact of HIV/AIDS on families with adolescents and children in Cambodia. Ministry of Social Affairs and the policy project; 2004.

[15] Alghanim S.A. An Analysis of High School Students' Knowledge and Attitudes Towards HIV/AIDS in Saudi Arabia: Implications for Health Education. Midal East Journal of family medicine, 2009:1(7):9.

[16] Maretha J Visser, Change in HIV-related stigma in South Africa between 2004 and 2016: a cross-sectional community study, AIDS Care, (1), (2018).

[17] UNAIDS . Report on the global AIDS epidemic. Geneva, Switzerland: World Health Organization, 2010.

[18] Thomas Coarm Research Unit. HIV and injecting drug users, Role of IEC. Institute of Education, University of London. International Journal of Drug Policy, 2005.

[19] Murray, S. M; Augustinavicius, J; Kaysen, D; Rao, D; Murray, L. K; Wachter, K; Annan, J; Falb, K; Bolton P. and Bass, J. K.. The impact of Cognitive Processing Therapy on stigma among survivors of sexual violence in eastern Democratic Republic of Congo: results from a cluster randomized controlled trial, Conflict and Health, 12, $1,(2018)$.

[20] Stoner burner RL. Behavior change communication in reducing HIV, African journal of AIDS research, 2003

[21] Sadoh AE, Sadoh WE, Fawole AO, Oladimeji A, Sotiloye O. Attitude of health care workers to patients and colleagues infected with human immunodeficiency virus. Journal of Social Aspects of HIV/AIDS. 2009;6(1):17-22.

[22] Schuster MA, Collins R, Cunningham WE, Morton SC, Zierler S, Wong M, et al. Perceived discrimination in clinical care in a nationally representative sample of HIV-infected adults receiving health care. J Gen Intern Med. 2005 Sep;20(9):807-13.

[23] Deacon H, Boulle A. Commentary: Factors affecting HIV/AIDS-related stigma and discrimination by medical professionals. International journal of epidemiology. 2007;36(1):185.

[24] WHO (2005). Yemen. Summary Country Profiles for HIV/AIDS Treatment Scale-Up. "Internet communicaton, [ 09,03,2009, att/ http://wwwwhoint/hiv/HIVCP_YEMpd"

[25] Louise Lambert. HIV and development challenges in Yemen: which grows fastest ? Health Policy and Planning. 2007;22:60-2.

[26] Strategic Framework for the Control and Prevention of HIV/AIDS in Republic or yemen. 2002.

[27] Jean-Baptiste Rachel. HIV/AIDS-related Stigma, Fear, and Discriminatory Practices among Healthcare Providers in Rwanda. Operations Research Results: U.S. Agency for International Development (USAID) by the Quality Assurance Project. Bethesda, MD:University Research Co., LLC; 2008. p. 1-23.

[28] Republic of Yemen, People living with HIV/AIDS rights,2009.

[29] Badahdah, A. ,Sayem N. \& Foote, CE. Development of a Yemeni AIDS stigma scale. AIDS Care Psychological and Socio-medical Aspects of AIDS/HIV. 2009, 21(6): 754-759. 
[30] Kermode $\mathrm{M}^{1}$, Holmes W, Langkham B, Thomas MS, Gifford S. HIV-related knowledge, attitudes and risk perception amongst nurses, doctors and other healthcare workers in rural India. Indian J Med Res. 2005 122(3):258-64.

[31] QAP Tanzania HIV Stigma Study Team. Evaluation of Knowledge, Attitudes, and Practices of Health Care Providers toward HIV-positive Patients in Tanzania. Operations Research Results. 2007. Published for the U.S. Agency for International Development (USAID) by University Research Co., LLC, Bethesda, MD.'

[32] Jean-Baptiste R. HIV/AIDS-related Stigma, Fear, and Discriminatory Practices among Healthcare Providers in Rwanda. Operations Research Results. Published for the U.S. Agency for International 2008. Development (USAID) by the Quality Assurance Project. Bethesda, MD: University Research Co., LLC.

[33] Abdel Rahim S., Elmagboul NSE., Abubaker H. and Amin M. Stigma and Discrimination against People Living With HIV Patients in Sudan. International Journal Of Current Medical And Pharmaceutical Research, 3(05):16551659;2017.

[34] Quality assurance project Tanzaina HIV stigma Study Team. Evaluation of knowledge,attitude and practices of health care providers toward HIV-positive patients in Tanzania. Operations Research Results: U.S. Agency for International Development (USAID)by University Research Co., LLC, Bethesda, MD; 2007.

[35] Reis C, Heisler M, Amowitz L, Moreland R, Mafeni J, Anyamele C, et al. Discriminatory attitudes and practices by health workers toward patients with HIV/AIDS in Nigeria. PLoS Medicine. 2005;2(8):743-52.

[36] Pulerwitz, Julie, Annie Michaelis, Ellen Weiss, Lisanne Brown, and Vaishali Mahendra. Reducing HIV-Related Stigma: Lessons Learned from Horizons Research and Programs. Public Health Reports, 2010;125(2): $272-81$. doi:10.1177/003335491012500218.

[37] Raja'a Y, Al-Hussein I. Knowledge, Attitude and Practice of Health Caregivers Towards HIV/AIDS in CDP Project Districts. "Internet communication,24,12,2014, att http://wwwmophp-yeorg/DocDB/docs /MoPHP_317_603pdf"

[38] Sallam S. A., Mahfouz A. A. R., Alakija W., Al-Erian R. A. Continuing medical education needs regarding AIDS among Egyptian physicians in Alexandria, Egypt and in the Asir Region, Saudi Arabia. AIDS Care. 1995;7(1):49.

[39] Fido A, Kazemi RA. Survey of HIV/AIDS knowledge and attitudes of Kuwaiti family physicians. family practice. 2002;19:682-4.

[40] Sallam S. A., Mahfouz A. A. R., Alakija W., Al-Erian R. A. Continuing medical education needs regarding AIDS among Egyptian physicians in Alexandria, Egypt and in the Asir Region, Saudi Arabia. AIDS Care. 1995;7(1):49.

[41] Askarian M, Hashemi Z, Jaafari P, Assadian O. Knowledge About HIV infection and attitude of nurssing Staff Toward patients with AIDS in Iran. Infection Control and Hospital Epidemilogy. 2006;27(1):47-50.

[42] Mahendra VS, Gilborn L, George B, Samson L, Mudoi R, Jadav S, et al. Reducing AIDS-related stigma and discrimination in Indian hospitals. Horizons Final Report. New Delhi: Population Council; 2006. p. 17. 